Revue Revue de l'histoire des religions

del'histoire des religions

Lieux de culte, lieux saints dans le judaïsme, le christianisme et l'islam

\title{
Lieux de culte, lieux saints dans le judaïsme, le christianisme et l'islam : Présentation
}

Dominique logna-Prat et Gilles Veinstein

\section{OpenEdition}

\section{Journals}

Édition électronique

URL : http://journals.openedition.org/rhr/4220

DOI : $10.4000 /$ rhr. 4220

ISSN : 2105-2573

Éditeur

Armand Colin

Édition imprimée

Date de publication : 1 octobre 2005

Pagination : 387-391

ISBN : 2200-92087-3

ISSN : 0035-1423

Référence électronique

Dominique logna-Prat et Gilles Veinstein, « Lieux de culte, lieux saints dans le judaïsme, le

christianisme et l'islam : Présentation », Revue de l'histoire des religions [En ligne], 4 | 2005, mis en ligne le 13 janvier 2010, consulté le 22 septembre 2020. URL : http://journals.openedition.org/rhr/4220

DOI : https://doi.org/10.4000/rhr.4220 


\section{Lieux de culte, lieux saints dans le judaïsme, le christianisme et l'islam Présentation}

Les catholiques contemporains vivent « une religion pèlerine » (D. Hervieu-Léger) et n'entretiennent plus qu'un lien assez lâche aux lieux des pratiques communautaires. Cette situation s'oppose à celle du christianisme ancien, solidement implanté dans des lieux (églises, paroisses). Au regard de l'histoire des religions, cette évolution est-elle propre au christianisme? Si oui, quelle est la marque des Réformes protestantes dans le rapport de l'Occident chrétien à la présence monumentale du divin ? Quel lieu la synagogue est-elle comparée à l'église ? Qu'en est-il des lieux saints en islam, tombeau, mosquée ou zâwiya ? Lieux de culte, lieux de prière (ou d'étude), lieux saints, lieux sacrés, sanctuaires : à quelles notions recourir pour comparer l'architecture des pratiques religieuses à travers l'histoire des trois religions du Livre ? C'est autour de ces questions d'une grande complexité qu'en avril 2003, à l'invitation du Centre Thomas More (L'Arbresle), une petite équipe d'historiens, d'historiens de l'art et de sociologues, venus des études juives, de celles des mondes chrétiens et de l'islam, s'est réunie avec pour simple objectif d'examiner de façon critique les outils conceptuels disponibles en matière de sainteté et de sacralité des lieux. Le (premier) résultat de cette confrontation est proposé ici à la lecture et soumis à la discussion critique de tous ceux qui cherchent à dépasser le cloisonnement des pratiques professionnelles en autant de champs interdisant une approche globale des constructions religieuses à travers le temps et l'espace. 
Si l'on en juge par les propos tenus dans les grandes Histoires des religions sur l'éternelle sacralité du rapport des hommes aux lieux de manifestation, de célébration ou d'invocation du divin, quelles que soient l'époque et la diversité des contextes sociaux, ou encore par le vague des grandes catégories d'usage courant en sociologie des religions sur les «pôles » constitutifs du religieux, une telle confrontation courait le risque de la dilution dans d'inutiles généralités.

Pour se garder d'un tel danger, les contributions réunies dans ce numéro sont animées d'un souci commun d'historiser la démarche et d'introduire dans les approches une pincée de relativisme. L'histoire contemporaine de l'Occident, aux $\mathrm{XIX}^{\mathrm{e}}$ et $\mathrm{XX}^{\mathrm{e}}$ siècles - qui, par le biais des anciens empires coloniaux, est aussi celle de la plus grande partie du monde - est, en effet, marquée par une sacralisation de la terre largement héritée du christianisme latin, transmise par des États-nations tout imprégnés d'un rapport affectif au sol de la patrie et à divers lieux d'incarnation de la mémoire collective. Le poids du legs est tel que notre actualité est encore nourrie de conceptions « occidentalo-centrées » qui nous amènent à lire à l'aune de la sacralité territoriale les dessous de cartes géostratégiques à l'œuvre, entre autres, dans les reconfigurations de l'Europe centrale et orientale, dans l'incertaine définition des limites de la communauté européenne, dans l'interminable conflit israélo-palestinien, bref, dans tous « ces espèces d'espace » (pour parler comme Perec) que l'on peine à qualifier parce qu'ils disent notre rapport émotionnel à la terre et aux lieux dont nos sociétés sont censément constituées. D'où la nécessité d'un retour à l'Histoire, ou plutôt aux Histoires des trois religions du Livre pour ressaisir une pluralité de conceptions.

Par commodité de classement et non par logique de transmission d'une religion à l'autre (il n'y a aucun lien génétique, en la matière, entre le judaïsme, le christianisme et l'islam, mais un jeu complexe d'interactions), ces histoires peuvent être abordées selon le fil chronologique en partant du judaïsme. On sait la complexité du rapport (réel, naturel ou allégorique) du judaïsme à la Terre sainte et aux lieux de la sacralité, à travers une longue histoire menant de l'espace originel des Hébreux à l'Israël contemporain en passant par les 
mondes divers de la diaspora. L'unicité et la centralité du Temple de Jérusalem dans le judaïsme ancien sont des questions bien connues. La lente genèse de la synagogue, qui est un lieu d'étude et de prière non sacralisé, l'est un peu moins, malgré la récente somme de L. I. Levine. Rappelant qu'elle « est une fonction et non un type architectural défini par la tradition », D. Jarrassé montre comment la synagogue s'est trouvée, au fil du temps, tiraillée entre deux modèles, le Temple de Salomon et l'église, qui ont tendu à lui imposer un caractère sacré qu'elle n'avait pas originellement. R. Azria examine ensuite la complexité du rapport aux lieux dans le monde juif contemporain, prenant en considération aussi bien les édifices à vocation profane dans lesquels s'est investi l'État d'Israël, que les lieux « emblématiques » des juifs diasporiques, tels les musées et autres « lieux de mémoire ».

L'examen de la question du lieu saint et sacré dans le monde chrétien est concentré sur trois époques clés de l'histoire de l'Occident (à notre grand regret, aucune contribution ne présente l'autre point de vue, fort contrasté, celui de l'Orient chrétien). Le premier christianisme marque une double rupture, d'une part, avec la sacralité diffuse du panthéisme païen, d'autre part, avec le Temple de Jérusalem, sans parler des procès d'intention lancés par les chrétiens dès le $\mathrm{IV}^{\mathrm{e}}$ siècle pour dénier toute sacralité aux synagogues. Dans sa contribution, C. Sotinel examine dans quelle mesure les lieux de culte chrétiens, conçus d'abord comme des maisons de prière relevant d'espaces privés sont peu à peu devenus, sous une forme monumentale leur assurant de la visibilité dans le paysage social, des lieux sacrés à la fin de l'Antiquité tardive, c'est-à-dire à une époque où le christianisme devient une religion reconnue, puis la religion officielle de l'Empire romain (début et fin du Ive siècle). Dans une étude à large spectre chronologique qui mène le lecteur $\mathrm{du} \mathrm{V}^{\mathrm{e}} \mathrm{au}$ XIII ${ }^{\mathrm{e}}$ siècles, D. Iogna-Prat montre comment le lieu de culte s'institue dans le rituel (la consécration d'église), qui de saint (parce que lieu de repos des saints) le rend sacré, puis au prix de quel effort doctrinal les clercs occidentaux parviennent à justifier le statut exceptionnel fait à l'église comme lieu « spécial » et «propre » aux manifestations théophaniques. Pour autant, la partie de l'église (en tant que bâtiment 
« spécial ») n'est jamais vraiment gagnée en Occident. Les hérétiques du Moyen Âge et les protestants, à l'époque moderne, reviennent largement aux conceptions des premiers temps du christianisme suivant lesquelles le lieu de l'assemblée n'a aucune importance en lui-même, puisque l'Église est constituée des «pierres vivantes » que sont les fidèles. O. Christin se penche sur la « dispute du temple », qui, au XVI ${ }^{\mathrm{e}}$ siècle, oppose catholiques et protestants, les amenant à des conceptions opposées des aménagements matériels de l'espace liturgique, qui mettent en jeu la place de la chaire et de l'autel, l'importance du mobilier et des arts figuratifs, ou encore la présence de tombes à l'intérieur des édifices cultuels. Dans ces querelles, ne s'exprime pas simplement la «sainte horreur» des protestants face à la « substance » donnée à l'église de pierre comme contenant de la communauté, mais plus globalement le problème des «médiations » avec le divin (médiations monumentales, iconiques, cléricales).

L'islam ne connait, à proprement parler, que trois lieux saints, de natures au demeurant différentes : Jérusalem, Médine et surtout La Mecque. Ce dernier lieu, en direction duquel prient les musulmans du monde entier et vers lequel affluent les pèlerins de toutes origines, est sacralisé par la présence de la Ka'ba. M. Chodkiewicz analyse, notamment à travers l'expérience mystique d'Ibn 'Arabi, les paradoxes de cet unique temple de l'islam, temple vide, «lieu du Sans lieu ». La mosquée, envisagée par O. Grabar, dans un aperçu général des différents monuments religieux musulmans, n'a pas connu le processus de sacralisation de l'église catholique. Elle n'est, le plus souvent, qu'un lieu, non exclusif d'ailleurs, de réunion et de prière. Mais d'autres lieux (maqâm) répondent, dans un large consensus que seuls rejettent les docteurs les plus rigoristes, à l'irrépressible besoin des fidèles de localiser le sacré, d'inscrire dans l'espace, au travers de rites, l'expression de la piété : ce sont les mashahid, généralement des sépultures, dotées de mausolées, et, le cas échéant, d'un complexe de bâtiments, dont des mosquées, que sanctifie la présence des restes d'un saint et à travers lesquels se diffuse sa baraka. M. Gaborieau consacre une monographie à un sanctuaire soufi de l'Inde, le dargâh de Nizamuddin à Delhi, dans 
lequel le saint sert d'intercesseur entre le fidèle et Dieu. La tombe du saint irradie l'espace, et dans le cas particulier étudié par G. Veinstein, de la conquête de terres infidèles par les Ottomans, elle voue et prépare ces dernières à l'islamisation.

Intériorisation ou extériorisation de la foi, universalité ou localisation de la présence divine, Domus Dei ou Domus sanctorum: telles sont quelques-unes des tensions qu'exprime l'opposition entre lieux de culte et lieux saints, dans les trois religions abrahamiques, à travers leurs différences théologiques et historiques. Toutes posent la question, mais de façons diverses, de la personne face à des lieux ressentis comme «spéciaux ». Affaire de présence sainte, d'inscription théophanique, voire de sacralité instituée : c'est à cette diversité des rapports à la sacralité de la terre que ce numéro de la Revue de l'histoire des religions voudrait introduire. 
